\title{
ASPIRADO TRAQUEAL DE CAVALOS CLINICAMENTE SADIOS DA RAÇA QUARTO DE MILHA APÓS PROVA DE TRÊS TAMBORES
}

\author{
(Tracheal aspiration of clinically healthy quarter \\ horses after three barrel competition)
}

\author{
MICHELOTTO JÚNIOR, P. V'; BIAVA, J. S²; GONÇALVES, R. C³; \\ CASSOU, F"; BONFÁ, A. F5; MACHADO, C. D ${ }^{5}$.
}

\author{
${ }^{1}$ Docente de Clínica e Cirurgia de Eqüinos - PUC - PR. \\ ${ }^{2}$ Pós-graduanda da Clínica Veterinária da FMVZ - Unesp / Botucatu - SP. \\ ${ }^{3}$ Docente da Clínica Veterinária da FMVZ - Unesp / Botucatu - SP. \\ ${ }^{4}$ Pós-graduanda de Medicina Veterinária da UFPR - PR. \\ ${ }^{5}$ Acadêmico de Medicina Veterinária da PUC - PR
}

\begin{abstract}
RESUMO - O objetivo do presente estudo foi avaliar, com o auxílio de endoscopia, a citologia do aspirado traqueal em vinte sete cavalos da raça Quarto de Milha, provenientes de Curitiba e Região Metropolitana, após prova de Três Tambores. Foi obtida secreção das vias aéreas por aspirado traqueal com cateter de polietileno introduzido no canal de trabalho do endoscópio, na altura da bifurcação traqueal. As lâminas citológicas foram preparadas por esfregaço e coradas pela técnica de panótico rápido e a contagem diferencial foi realizada em 500 células através de microscopia óptica com aumento de 1000 vezes. Nenhum dos cavalos apresentou anormalidade, incluindo epistaxe, ao exame clínico. Entretanto, à citologia detectou-se hemossiderófagos em três animais, sugerindo que alguns deles poderiam estar sofrendo de hemorragia pulmonar subclínica. A contagem diferencial de células do aspirado traqueal foi em média de: $44,09 \pm 35,68 \%$ de células epiteliais; $1,10 \pm 2,18 \%$ de células caliciformes; $23,10 \pm 35,93 \%$ de neutrófilos; $0,13 \pm 0,37 \%$ de linfócitos; $0,91 \pm 2,81 \%$ de eosinófilos; $30,57 \pm$ $23,62 \%$ de macrófagos e $0,13 \pm 0,93 \%$ de hemossiderófagos. Em conclusão, baseado no presente trabalho, a avaliação das populações celulares com o aspirado traqueal pode fornecer ao clínico importantes informações adicionais, especialmente acerca de processos inflamatórios das vias aéreas inferiores e hemorragia pulmonar.
\end{abstract}

PALAVRAS-CHAVE: citologia; aspirado traqueal; eqüino; Quarto de Milha

ABSTRACT - The aim of the present study was to evaluate through endoscopy the tracheal aspiration cytology in twenty seven Quarter Horses from Curitiba and surroundings, following the Three Barrel Competittion. Upper respiratory tract secretion was obtained by tracheal aspiration using a polyethylene catheter introduced through the endoscopic fiberoptic working channel, at the level of tracheal bifurcation. Cytologic slides were prepared by smear and stained by diff-quick technique and the differential was performed in 500 cells counting by $1,000 \mathrm{X}$ optic microscopy. None of the horses presented abnormality, including epixtasis, at the clinical examination. However, hemosiderophages were detected at cytology in three animals, suggesting that some may be suffering of subclinical pulmonary hemorrhage. Differential cell counting of tracheal aspiration results were, in average: $44.09 \pm 35.68 \%$ of epithelial cells; $1.10 \pm 2.18 \%$ of Globet cells; $23.10 \pm 35.93 \%$ of neutrophils; $0.13 \pm 0.37 \%$ of lymphocytes; $0.91 \pm 2.81 \%$ of eosinophils; $30.57 \pm 23.62 \%$ of macrophages and $0.13 \pm 0.93 \%$ of hemosiderophages. In conclusion, based in the present study, the evaluation of cellular populations with the tracheal aspiration may offer important additional information to the clinician, particularly about the inflammatory processes of lower respiratory tract and pulmonary bleeding.

Keywords: Cytology; tracheal aspirate; equine; Quarter Horse

\section{INTRODUÇÃO}

O exame citológico das vias aéreas inferiores pode ser realizado através de aspirado traqueal (por endoscopia) e trans-traqueal, além de lavados traqueal, traqueobrônquico e broncoalveolar que auxiliam na avaliação das doenças do trato respiratório (FOGARTY, 1990; ERICKSON e POOLE, 2002). O aspirado traqueal foi introduzido primeiramente na medicina humana como método de colheita de amostras do trato respiratório para análises bacterianas e citológicas (PECORA, 1959), e é intensamente utilizada na medicina veterinária, desde a década 
MICHELOTTO JÚNIOR, P. V. et al.

de 70 do século $X X$. A técnica foi adaptada por MANSMANN e KNIGHT (1972) e BEECH (1975) podendo, a citologia dessas amostras, ser utilizada na avaliação de cavalos com várias doenças respiratórias, inclusive as doenças respiratórias crônicas (HOFFMAN e VIEL 1997).

A aspiração de secreções da traquéia para análise citológica ou identificação de agentes infecciosos, pode ser realizada por via percutânea (transtraqueal) ou através do canal de trabalho do endoscópio (HODGSON e HODGSON, 2003). Ambas são relativamente fáceis de serem feitas a campo. A técnica transtraqueal possui a vantagem de eliminar a passagem pela cavidade nasal e porções do trato respiratório superior, eliminando o risco de contaminação da amostra por microorganismos da flora local da nasofaringe (HEWSON e VIEL, 2002). A colheita através do canal de trabalho do endoscópio utilizando uma sonda de polietileno, recupera material para exame citológico, sendo contudo inviável para a análise bacteriológica. Porém o endoscópio oferece a vantagem da visualização do trato respiratório no momento da colheita, permitindo a avaliação da mucosa da traquéia e a graduação da quantidade de secreção, o que pode auxiliar na interpretação dos resultados citológicos. Atualmente a colheita de amostras por aspirado traqueal, com a utilização do endoscópio, tem se tornado rotina (HODGSON e HODGSON, 2003).

A avaliação citológica do aspirado traqueal é feita pela contagem total de células na câmara de Neubauer, e pela avaliação diferencial dos tipos celulares. Para esta última, diferentes técnicas de coloração podem ser utilizadas, sendo empregadas a Diff-Quick, Wright-Giemsa, Leishman's, Azul da Prússia, My-Grunwald, Azul de Toluidina e Romanovski (HEWSON e VIEL, 2002; HODGSON e HODGSON, 2003). A coloração de Azul da Prússia facilita a visualização de hemosiderófagos (BIAVA, 2005), e para melhor visualizar mastócitos podem ser empregadas as colorações de Leishman's e o Azul de Toluidina (HEWSON e VIEL, 2002; HODGSON e HODGSON, 2003). Uma lâmina adequada para a avaliação citológica deve conter células de todos os níveis da árvore pulmonar, incluindo células epiteliais colunares e cuboides e macrófagos alveolares (SWEENEY et al., 1992; CLARK et al., 1995; HEWSON e VIEL, 2002; HODGSON e HODGSON, 2003).

Pequenas quantidades de células epiteliais são encontradas no aspirado traqueal de cavalos saudáveis, podendo haver um número aumentado quando a colheita é obtida com o uso do endoscópio. Há a observação, ainda não substanciada, do aumento do número de células não ciliadas e de tufos de cílios, observados em cavalos com baixo rendimento (HODGSON e HODGSON, 2003).
O macrófago alveolar é o mais abundante tipo de célula inflamatória no aspirado traqueal de cavalos normais (HODGSON e HODGSON, 2003). O seu citoplasma pode conter material endógeno ou exógeno, fagocitado nas vias aéreas, inclusive eritrócitos ou hemossiderina sendo chamado hemosiderófago, neste caso atestando hemorragia pulmonar (ZINKL, 2002; OLIVER et al., 2003). Hemosiderófagos são eliminados lentamente das vias aéreas, podendo estar presentes meses após a ocorrência de hemorragia pulmonar (HODGSON e HODGSON, 2003).

Neutrófilos usualmente são encontrados em pequeno número no aspirado traqueal de cavalos normais. Uma porcentagem inferior a $30 \%$ no aspirado traqueal pode ser considerada dentro dos limites normais em cavalos atletas jovens (HODGSON e HODGSON, 2003). Quantidades elevadas podem ser detectadas em processos inflamatórios como a doença inflamatória das vias aéreas (DIVA), a bronquite crônica, a obstrução recorrente das vias aéreas (ORVA) e na hemorragia pulmonar de esforço (BEECH, 1975; HODGSON e HODGSON, 2003; BIAVA et al., 2006).

Para a avaliação citológica da amostra, uma lâmina pode ser feita no próprio local da colheita, para se realizar a contagem diferencial de células. Para maior acurácia na interpretação dos resultados, muitos citologistas preferem realizar a contagem diferencial de, no mínimo, cinco células por campo de visão, no maior aumento $(1000 X)$ ou 300 a 500 células por lâmina (MAZAN e HOFFMAN, 2003).

Embora vários estudos abordem citologicamente o sistema respiratório em animais de corrida, ainda é escassa a literatura em animais de provas rurais, tais como três tambores, seis balizas e laço (BACCARIN, 2005). Embora em estudo anterior tenha sido feita a citologia do sistema respiratório em cavalos sadios da raça Quarto de Milha em treinamento, esta análise foi realizada apenas no dia seguinte às provas de três tambores e seis balizas (BIAVA et al., 2005). Deste modo, o objetivo do presente estudo foi o de avaliar clinica e citologicamente o aparelho respiratório de cavalos em provas rurais logo após o exercício de competição, utilizando-se para o experimento cavalos da raça Quarto de Milha após a prova de três tambores .

\section{MATERIAL E MÉTODOS}

Foram utilizados 27 eqüinos da raça Quarto de Milha, sendo 9 machos castrados, 4 machos não castrados e 14 fêmeas, variando entre 3 a 13 anos de idade, e pesando em média $500 \mathrm{Kg}$, todos clinicamente sadios, provenientes de Curitiba e região metropolitana, Estado do Paraná. Os cavalos eram 
Aspirado traqueal de cavalos clinicamente sadios da raça quarto de milha após prova de três tambores

mantidos em piquetes durante o dia e encocheirados durante a noite, alimentados com feno, ração comercial e água ad libitum, além de vermifugados em intervalos de 60 dias. O regime de exercícios era de uma hora diária, por seis dias na semana, incluindo a participação em campeonatos de tambor e baliza.

Todos os cavalos foram avaliados clinicamente quanto à freqüência respiratória, freqüência cardíaca, temperatura retal, reflexo de tosse, assim como a presença de epistaxe e / ou secreções nas narinas, alterações sugestivas de hemorragia pulmonar, e outras doenças pulmonares e de garganta. Trinta minutos após a prova de três tambores foram realizadas as broncoscopias em todos os animais e somente aqueles que apresentavam secreção nas vias aéreas, observada por endoscopia, foram incluídos no experimento.

Foi utilizado um endoscópio flexível (Colonoscópio CF 140L, Olympus Company, EUA com 1,70 metros de comprimento e $12,0 \mathrm{~mm}$ de diâmetro externo, com fonte de luz fria 150 Watts), introduzido na narina em direção à traquéia e brônquios, com contenção mecânica através do cachimbo. No trato respiratório superior e inferior, pesquisou-se a presença de: secreção nasal e epistaxe, hiperplasia folicular (HFL), hemiplegia laríngea, deslocamento dorsal de palato mole (DDPM), secreção traqueal, alterações da bifurcação traqueal, alterações nos brônquios principais e relacionadas a coloração da mucosa traqueobrônquica. A presença de hemorragia pulmonar induzida por exercício $(E I P H)$ foi observada, e quando houve necessidade, graduada de Grau I a Grau V, segundo escala de Eppinger (EPPINGER, 1990). Após a introdução do endoscópio nas vias aéreas realizou-se a colheita da secreção pela visualização da traquéia e a aspiração, realizada através de um cateter de polietileno, introduzido pelo canal de trabalho do endoscópio e acoplado a uma seringa de $20 \mathrm{ml}$. O local de colheita foi o mais próximo possível da carina. Imediatamente após a colheita da secreção, foram feitos vários esfregaços em lâminas de vidro para não permitir que as células degenerassem, secados ao ar e corados no local pela técnica de Romanovski (ZINKL, 2002).

Para a análise diferencial de células foram contadas 500 células no aumento de 1000X (HEWSON e VIEL, 2002), diferenciando-se as proporções dos diferentes tipos celulares (células epiteliais, macrófagos, linfócitos, neutrófilos, eosinófilos e hemossiderófagos).

\section{RESULTADOS}

Nenhum dos animais necessitou de prévia sedação para o exame clínico. Segundo o exame físico realizado, aproximadamente 15 minutos após a prova observaram-se 39,7 $\pm 6,7$ movimentos respiratórios por minuto, 82,29 $\pm 9,5$ batimentos cardíacos por minuto. Nenhum dos animais apresentou epistaxe ou secreção mucosa nasal ao exame externo.

Os resultados foram obtidos e tabulados (QUADRO 1). Dos 27 cavalos, somente 18 apresentavam secreção ao longo da traquéia. As secreções, visíveis a endoscopia foram classificadas segundo escore de 1-5 (HOLCOMBE, 2005). Os cavalos de número 1, 3, $4,16,17,18,19$ e 27 apresentam secreção de grau I $(29,63 \%)$; os cavalos $13,15,21$, de grau II $(11,11 \%)$; os cavalos $8,9,22,23,24$ de grau III $(18,51 \%)$; o cavalo 11 , de grau IV $(3,70 \%)$. Não foi observada a presença de secreção nos animais restantes.

As traquéias dos cavalos de número $4,9,12$, $13,14,17,18,24,26$ e 27 apresentavam-se hiperreativas ; no cavalo 3 havia secreção seromucosa; no cavalo 15 secreção muco-purulenta e no 22 a traquéia apresenta-se hiperêmica e hiperreativa. As traquéias dos animais restantes apresentavam-se normais (QUADRO 1).

Os cavalos de número $1,2,3,6,10,15,16,17$, $19,20,21,22,23,24$ e 26 não apresentam alterações na bifurcação traqueal (carina), já os animais de número 4, 9 e 27 apresentam carina hiperêmica e edemaciada e o cavalo 18 apresentava somente hiperêmia da carina (QUADRO 1).

A observação da epiglote resultou normal na maioria, com exceção do cavalo número 24 que apresentou epiglote visualmente de menor tamanho. Com relação a graduação dos folículos linfóides, os cavalos de número 9, 22, 24 apresentaram hiperplasia folicular linfóide de grau 2 , somente o cavalo de número 1 apresentou hiperplasia de grau 3 , enquanto os demais apresentaram-se com grau 1. Os cavalos de número 3, 5,13 e 25 não apresentaram alteração relevante (QUADRO 1).

Os animais de número 5, 13 e 25 apresentaram pequena deformação na cartilagem aritenóide. O restante apresentou neurolaringopatia Grau I. Somente os cavalos de número 1, 2, 4, 7 e 9 apresentaram deslocamento dorsal do palato mole. Foi observado a presença de secreção mucopurulenta junto as aberturas faringeanas das bolsas guturais dos cavalos 4 e 11 (QUADRO 1). 
QUADRO 1 - ACHADOS ENDOSCÓPICOS E ALTERAÇÕES OBSERVADAS DURANTE REALIZAÇÃO DO ASPIRADO TRAQUEAL DE CAVALOS DA RAÇA QUARTO DE MILHA EM PROVA DE TRÊS TAMBORES NA REGIÃO METROPOLITANA DE CURITIBA, 2006. $(n=27)$

\begin{tabular}{|c|c|c|c|c|c|c|c|c|c|}
\hline \multirow[b]{2}{*}{ Animal } & \multicolumn{4}{|c|}{ Vias aéreas inferiores } & \multicolumn{5}{|c|}{ Vias aéreas superiores } \\
\hline & $\begin{array}{c}\text { Hemorragia } \\
\text { Pulmonar } \\
\text { (Grau) }\end{array}$ & Carina & Traquéia & $\begin{array}{c}\text { Secreção } \\
\text { Traqueal } \\
\text { (Grau) }\end{array}$ & $\begin{array}{l}\text { Bolsa } \\
\text { Gutural }\end{array}$ & $\begin{array}{c}\text { Hemiplegia } \\
\text { Laríngea } \\
\text { (Grau) }\end{array}$ & DDPM & Epiglote & $\mathrm{HFL}$ \\
\hline 1 & - & - & - & I & - & 1 & Intermitente & - & 3 \\
\hline 2 & - & - & - & NR & - & Normal & presente & - & 1 \\
\hline 3 & - & - & SS & 1 & - & 1 & - & - & - \\
\hline 4 & - & HE/ED & $\mathrm{HR}$ & I & SMP & 1 & presente & - & 1 \\
\hline 5 & NR & - & - & NR & - & - & - & - & - \\
\hline 6 & - & - & - & NR & - & 1 & - & - & 1 \\
\hline 7 & III-IV & - & - & NR & - & 1 & presente & - & 1 \\
\hline 8 & & - & - & III & - & 1 & - & - & 1 \\
\hline 9 & - & HE/ED & $\mathrm{HR}$ & III & - & 1 & presente & - & 2 \\
\hline 10 & - & Normal & - & NR & - & 1 & - & - & 1 \\
\hline 11 & I & - & - & IV & SM & 1 & - & - & 1 \\
\hline 12 & IV & - & $\mathrm{HR}$ & NR & - & 1 & - & - & 1 \\
\hline 13 & II & - & $\mathrm{HR}$ & II & - & - & - & - & - \\
\hline 14 & III & - & $\mathrm{HR}$ & NR & - & 1 & - & - & 1 \\
\hline 15 & - & - & SMP & II & - & 1 & - & - & 1 \\
\hline 16 & - & - & - & I & - & 1 & - & - & 1 \\
\hline 17 & - & - & $\mathrm{HR}$ & I & - & 1 & - & - & 1 \\
\hline 18 & - & $\mathrm{HE}$ & HR & I & - & 1 & - & - & 1 \\
\hline 19 & - & - & - & 1 & - & 1 & - & - & 1 \\
\hline 20 & III & - & - & NR & - & 1 & - & - & 1 \\
\hline 21 & - & - & - & II & - & 1 & - & - & 1 \\
\hline 22 & - & - & $\mathrm{HE} / \mathrm{HR}$ & III & - & 1 & - & - & 2 \\
\hline 23 & - & - & - & III & - & 1 & - & - & 1 \\
\hline 24 & - & - & $\mathrm{HR}$ & III & - & 1 & - & - & 2 \\
\hline 25 & NR & - & - & NR & - & - & - & - & - \\
\hline 26 & NR & Normal & $\mathrm{HR}$ & NR & - & 1 & - & - & 1 \\
\hline 27 & NR & HE/ED & $H R$ & 1 & - & 1 & presente & HE / ED & 1 \\
\hline
\end{tabular}

$(-)=$ NORMAL; DDPM= DESLOCAMENTO DORSAL DE PALATO MOLE; HFP=HIPERPLASIA FOLICULAR LINFÓIDE; NR = NÃO REALIZADO; SM= SECREÇÃO MUCOSA; SS= SECREÇÃO SEROMUCOSA; SMP= SECREÇÃO MUCOPURULENTA; HE= HIPEREMMICA, HR= HIPEREATIVA, ED= EDEMACIADA;

O exame endoscópico evidenciou sangramento pulmonar em 7 animais, que variou conforme a classificação de EPPINGER (1990). Hemorragia de Grau I foi visível somente no cavalo 11; de grau II no cavalo 13; de grau III nos cavalos 8, 14, 20 e de grau IV nos cavalos 7 e 12 .
A contagem diferencial média de células do aspirado traqueal foi de $44,09 \pm 35,68$ de células epiteliais; $1,10 \pm 2,18$ de células caliciformes; 23,10 $\pm 35,93$ de neutrófilos; $0,13 \pm 0,37$ de linfócito; 0,91 $\pm 2,81$ eosinófilos; $30,57 \pm 23,62$ de macrófagos e, $0,13 \pm 0,93$ de hemossiderófagos (TABELA 1). 
Aspirado traqueal de cavalos clinicamente sadios da raça quarto de milha após prova de três tambores

TABELA 1 - LEITURA DIFERENCIAL E TOTAL DE LEUCÓCITOS DO ASPIRADO TRAQUEAL PRODUTIVO DE 18 DO TOTAL DE 27 CAVALOS DA RAÇA QUARTO DE MILHA EM PROVA DE TRÊS TAMBORES NA REGIÃO METROPOLITANA DE CURITIBA NO ANO DE 2006. $(n=18)$

\begin{tabular}{ccccccccccc} 
& \multicolumn{3}{c}{ Células (\%) } & \multicolumn{3}{c|}{ Leucócitos (\%) } & \multicolumn{4}{c}{ Macrófagos (\%) } \\
\hline Número & Epiteliais & Caliciformes & Neutrófilos & Linfócitos & Eosinófilos & Total & HSF & ME & CG \\
\hline 1 & 35,87 & 0,62 & 5,50 & 0,62 & 3,25 & 52,38 & 1,88 & 0,33 & 1,66 \\
2 & 41,50 & 1,12 & 38,62 & 0 & 5,62 & 12,88 & 0 & 2,20 & 1,40 \\
3 & 7,12 & 0 & 82,25 & 0 & 0,12 & 10,50 & 0 & 0,50 & 0 \\
4 & 57,00 & 0,62 & 34,88 & 0,12 & 0,25 & 7,00 & 0 & 1,25 & 1,25 \\
5 & 22,75 & 0,25 & 71,88 & 0 & 0 & 5,12 & 0 & 0 & 0 & 0 \\
6 & 78,50 & 3,88 & 3,00 & 0,12 & 2 & 12,38 & 0 & 2,00 & 2,00 \\
7 & 44,87 & 1,00 & 11,12 & 0 & 0,38 & 43,62 & 0,25 & 2,00 & 0,50 \\
8 & 36,62 & 0,12 & 45,50 & 0,38 & 0 & 17,12 & 0 & 3,00 & 2,00 \\
9 & 21,62 & 0,25 & 67,62 & 0,38 & 0,25 & 10,00 & 0 & 0,50 & 1,25 \\
10 & 51,37 & 1,88 & 8,88 & 0 & 0 & 38,62 & 0 & 1,00 & 2,00 \\
11 & 41,00 & 3,00 & 0,62 & 0 & 0 & 55,00 & 0,25 & 2,75 & 2,00 \\
12 & 12,00 & 0,38 & 1,88 & 0,75 & 3,5 & 81,5 & 0 & 1,50 & 0,75 \\
13 & 55,62 & 0,75 & 0,50 & 0 & 0 & 42,88 & 0 & 2,33 & 2,00 \\
14 & 50,66 & 0,33 & 3,33 & 0 & 0,67 & 45,00 & 0 & 2,75 & 1,50 \\
15 & 54,12 & 4,38 & 0,50 & 0 & 0 & 41,00 & 0 & 2,75 & 0,75 \\
16 & 36,88 & 0,38 & 36,38 & 0 & 0 & 26,38 & 0 & 2,00 & 0 \\
17 & 73,00 & 1,00 & 0 & 0 & 0 & 26,00 & 0 & 3,00 & 0,50 \\
18 & 73,20 & 0 & 3,40 & 0 & 0,4 & 23,00 & 0 & 0 & 0 \\
\hline Média & 44,09 & 1,108 & 23,103 & 0,13 & 0,913 & 30,57 & 1,31 & 1,75 & 1,15 \\
Desvio & 35,68 & 2,18 & 35,93 & 0,37 & 2,81 & 23,62 & 0,93 & 1,5 & 0,83 \\
\hline
\end{tabular}

HSF = HEMOSSIDERÓFAGO, ME = MACRÓFAGO ESPUMOSO; CG = CÉLULAS GIGANTES

Os valores da contagem diferencial de células e percentual de hemossiderófagos (contados como parte do total de macrófagos) encontram-se resumidos na TABELA 1.

Hemossiderófagos foram observados nos cavalos de número 1,7 e 11.

\section{DISCUSSÃO}

Neste estudo observou-se que a avaliação clínica não mostrou alterações relevantes, uma vez que todos os animais utilizados eram saudáveis e clinicamente normais. Estes resultados são semelhantes a estudos anteriores, onde se observou que as freqüências cardíaca e respiratória podem estar elevadas logo após o exercício e não apresentar alterações durante o repouso, mesmo em cavalos com algum grau de Hemorragia Pulmonar (BACCARIN, 2005).

A grande vantagem do uso da endoscopia para a colheita de material nas vias aéreas é a visualização das suas estruturas, definindo com isso, alterações anatômicas como: hiperplasia folicular linfóide e tamanho da epiglote e deslocamento dorsal do palato mole, além de permitir a graduação da quantidade de secreção na traquéia (QUADRO 1) (ROY e LAVOIE, 2003; HODGSON e HODGSON, 2003). Além disso, pode-se estimar a severidade da EIPH pela avaliação da quantidade de sangue presente nas vias aéreas, pois a presença de epistaxe foi observada somente em 0,25 a $13 \%$ dos cavalos Puro Sangue Inglês de corrida acometidos por EIPH (ERICKSON e POOLE, 2002). Nos cavalos da raça Quarto de Milha de provas esta incidência ainda não foi estudada, contudo dos 7 indivíduos que evidenciaram EIPH diagnosticado pela endoscopia, nenhum apresentou epistaxe.

Como mencionado anteriormente e citado por HODGSON e HODGSON (2003), a possibilidade de se estimar a quantidade de secreção ao longo das vias aéreas constituiu outro fator importante para o uso do endoscópio para a colheita de secreção. Quantidades moderadas de muco visível na traquéia estão relacionadas com inflamação das vias aéreas e com queda no rendimento em cavalos atleta (HOLCOMBE, 2005). Assim sendo, no presente estudo a utilização da técnica de aspirado traqueal com auxílio de endoscopia mostrou-se importante instrumento na avaliação da inflamação das vias aéreas inferiores e para a colheita de material para 
avaliação citológica e diagnóstico das afecções respiratórias em eqüinos.

A citologia do aspirado traqueal é referidamente mais específica do que somente o exame endoscópico, devido à observação de células características dos processos hemorrágicos, como os hemossiderófagos, que podem permanecer meses nas vias aéreas após um episódio de hemorragia pulmonar (HODGSON e HODGSON, 2003). Como observado no presente estudo, os achados citológicos se tornam muito úteis na interpretação e formulação de diagnóstico diferencial, mesmo quando não se consegue visualizar alterações macroscópicas à endoscopia.

Com relação à EIPH, os resultados deste trabalho são similares a outro estudo realizado nos cavalos da raça Quarto de Milha (BIAVA et al., 2006), onde houve uma incidência de sangramento, visível ao endoscópio após exercício intenso, menor que em cavalos da raça Puro Sangue Inglês (EPPINGER, 1990). O sangramento pode ser detectado por endoscopia 30 a 60 minutos após o exercício, que é o tempo necessário para a drenagem do sangue das vias aéreas mais profundas para as de grande calibre (ERICKSON e POOLE, 2002).

A coloração de Romanovski indicada por ZINKL (2002) e utilizada neste estudo, permitiu adequada visualização de todos os tipos celulares, porem o baixo número de hemossiderófagos pode ser atribuído à falta de uma coloração específica para esta célula, como o azul da Prússia, a qual facilita a visualização de pigmentos de hemossiderina (BIAVA et al., 2006).

Para a colheita do Aspirado traqueal destes animais não foi utilizado nenhum tipo de anestésico, o que facilitou o exame das vias aéreas superiores, corroborando os achados de DOUCET e VIEL (2002), que afirmam não ser necessária a sedação.

No presente estudo observou-se um aumento de leucócitos, em particular neutrófilos, e ainda a presença de muco em grande quantidade. $O$ processo inflamatório nas vias aéreas passa muitas vezes despercebido por treinadores e proprietários, e somente o exame clínico detalhado, incluindo a endoscopia e a citologia, pode informar a real situação do trato respiratório. Alergenos ambientais, do ar e das baias, podem causar inflamação nas vias aéreas e acúmulo de muco traqueal. Estes contaminantes incluem endotoxinas, esporos de fungos, pó de feno e/ou forragem e ar poluente (HOLCOMBE, 2005).

A utilização de cavalos da raça Quarto de Milha em provas de três tambores foi interessante neste estudo, pois apesar da limitada amostragem, pôdese obter dados originais da avaliação citológica do aspirado traqueal para animais clinicamente sadios da raça Quarto de Milha.
A ocorrência da EIPH pode ter sido maior do que se observou no presente estudo, uma vez que não foi utilizada coloração específica para hemossiderófagos, marcadores específicos para a hemorragia subclínica crônica. Assim sendo, se nos utilizarmos colorações específicas, tais como o Azul da Prússia (BIAVA, 2005), poderia ter sido visualizado número ainda maior de hemosiderófagos, identificando uma ocorrência maior ainda da EIPH.

Em conclusão, o aspirado traqueal mostrou ser uma boa técnica para diagnóstico das afecções das vias aéreas, refletindo sua situação geral, sugerindo que fatores como manejo alimentar e condição das baias constituem uma mescla variável de agentes que podem influenciar sua celularidade.

\section{REFERÊNCIAS}

BACCARIN, R. Y.A. Diagnóstico e tratamento das pneumopatias de esforço. In: II Simpósio Internacional do Cavalo Atleta e IV Semana do Cavalo SIMCAV. 2005, Belo Horizonte, Anais II Simpósio Internacional do Cavalo Atleta. Minas Gerais: Universidade Federal de Minas Gerais, 2005, p. 12-28.

$\mathrm{BEECH}$, J. Cytology of traceobronchial aspirates in horses. Veterinary Pathology, v. 24 n 12, p. 157 -64, 1975.

$\mathrm{BEECH}, \mathrm{J}$. Tracheobronchial aspirates. In: BEECH, J. Equine Respiratory Disorders. Philadelphia, Lea \& Febiger, ed. p. 41, 1991.

BIAVA, J.S.; GONÇALVES, R.C.; ZANOTTO, G.M.; TONIN, V.R.; CARON, P.E.; BIONDO, A.W. e TELLES, J.E.Q. Uso da citocentrífuga e colorações especiais no exame citológico do lavado broncoalveolar em cavalos. Revista Acadêmica, v.3, n. 4, p.47-50. 2005.

BIAVA, J. S; GONÇALVES, R C; DONRBUSCH, P. T; ZANOTTO, G. M; BIONDO, A. W. Avaliação Cínica e Citológica do trato respiratório de cavalos da raça Quarto de Milha após exercício. Archives of Veterinary Science, v 11, n. 1, p. $60-65,2006$.

CLARK, C. K.; LESTER, G. D.; VETRO, T.; RICE, B. Bronchoalveolar lavage in horses: effect of exercise and repeated sampling on cytology. Australian Veterinary Journal, v. 72, p. 249-252, 1995.

DOUCET, M. Y.; VIEL, L. Clinical, radiographic, en- 
Aspirado traqueal de cavalos clinicamente sadios da raça quarto de milha após prova de três tambores

doscopic, bronchoalveolar lavage and lung biopsy findings in horses with exercise-induced pulmonary hemorrhage. Canadian Veterinary Journal, v. 43, p 195-202, 2002.

EPPINGER, M. Hemorragia pulmonar de esforço e o desempenho de eqüinos PSI \{Equus caballus\} em corridas de galope no jockey club do Paraná. 1990. Dissertação (Mestrado) - Universidade Federal do Paraná, Curitiba.

ERICKSON, H. H.; POOLE, D. C. Exercise-induced pulmonary hemorrhage. In: LEKEUX, P. Equine Respiratory Diseases. 2002. Ithaca, NY. Disponível em <http://www.ivis.org/special_books/lekeux/erickson/ chapter_frm.asp?LA=1>. Acesso em: 06.set.2006.

FORGARTY, U. Evaluation of a bronchoalveolar lavage tecnique. Equine Veterinary Journal, v. 3, p 174-176, 1990.

HEWSON, J e VIEL, L. Sampling, microbiology and cytology of the respiratory tract. In: LEKEUX, P. Equine Respiratory Diseases. 2002. Disponível em <http://www.ivis.org/special_books/Lekeux/viel/ chapter_frm.asp?LA=1 >. Acesso em: 06.set.2006.

HODGSON, J.L. ; HODGSON, D.R. Tracheal aspirates: indications, technique and interpretation. In: ROBINSON, N.E. Current Therapy in Equine Medicine, 5.ed., St. Louis: Saunders, 2003, p.401-406.

HOFFMAN, A. M.; VIEL, L. Techniques for sampling the respiratory tract of horse. Veterinary Clinics of North America: Equine Practice, v. 13, p. 463-465, 1997.

HOLCOMBE, S. J. Epidemiology of airway inflammation and mucus in horses. In Proceedings: American Association of Equine Practitioners, v. 51, p: 337 - 340, 2005.

MANSMANN R. A.; KNIGHT, H. D. Transtracheal aspiration in the horse. Journal of the American Veterinary Medical Association, v. 160, p. 1527, 1972.

MAZAN, M. R.; HOFFMAN, A. M. Clinical techniques for diagnosis of inflammatory airway disease in the horse. Clinical Tecniques in Equine Pratice. v. 2, p. $238-357,2003$.

PECORA, D. V. A method of securing uncontamined tracheal secretions for bacterial examination. Journal of Thoracic Surgery, v. 37, p. $653-654,1959$.

OLIVER, O.; STAMPFLI, H.; AQUILERA, E. Enfermedades respiratórias de interes en el caballo de deporte. In: Conferencia Internacional de Caballos de Deporte - CICADE. 2003, Curitiba. Anais. Conferencia Internacional de Caballos de Deporte. Curitiba: Pontifícia Universidade Católica do Paraná, 2003, p. 15-22.

ROY, M. F.; LAVOIE, J. P. Tool for the diagnosis of equine respiratory disorders. Veterinary Clinics of North America: equine practice, v 19, p 1-7, 2003.

SWEENEY. C. R.; ROSSIER, Y.; ZIEMER, E. L. Effect of lung site and fluid volume on results of bronchoalveolar lavage fluid analysis in horses. American Journal of Veterinary Research, v. 53, p 1376-1379, 1992.

WILKINS, P. A.; BAKER, J. C.; AMEST, T. R. Doenças do sistema respiratório. In: SMITH, B. Medicina Interna de Grandes Animais. 3 ed. Barueri-SP: Manole, 2006, p. 3-14.

ZINKL, J.G. Lower respiratory tract. In: COWELL, R.L. \& TYLER, R.D. Diagnostic Cytology and Hematology of the Horse. 2 ed. St. Louis, Missouri: Mosby, 2002, p. 73-86.

Recebido para publicação:

$16 / 11 / 2006$

aprovado: 